Editorial

\title{
Immigration from the Immigrants' Perspective: Analyzing Survey Data Collected among Immigrants and Host Society Members
}

\author{
Alice Ramos ${ }^{1, *}$, Eldad Davidov ${ }^{2,3}$, Peter Schmidt ${ }^{4}$, Marta Vilar Rosales ${ }^{1}$ and Dina Maskileyson ${ }^{2}$ \\ ${ }^{1}$ Institute of Social Sciences, University of Lisbon, 1600-189 Lisbon, Portugal; E-Mails: alice.ramos@ics.ulisboa.pt (A.R.), \\ marta.rosales@ics.ulisboa.pt (M.V.R.) \\ 2 Institute of Sociology and Social Psychology, University of Cologne, 50923 Cologne, Germany; \\ E-Mails: e.davidov@uni-koeln.de (E.D.),dmaskile@uni-koeln.de (D.M.) \\ 3 University Research Priority Program "Social Networks," University of Zurich, 8006 Zurich, Switzerland \\ ${ }^{4}$ Department of Political Science, University of Giessen, 35390 Giessen, Germany; \\ E-Mail: peter.schmidt@sowi.uni-giessen.de \\ * Corresponding author
}

Submitted: 8 December 2019 | Published: 27 December 2019

\begin{abstract}
Immigration has been one of the most crucial global phenomena, changing the fabric of many societies, and a topic of substantial research. Much of this research has focused on how the host society views immigrants and immigration, or on the societal factors influencing the latter. The goal of this thematic issue is to present different studies focusing on various aspects of immigration from a perspective that has not been often viewed under the magnifying glass so far, but which is of major importance: looking at immigration from the immigrants' point of view.
\end{abstract}

\section{Keywords}

adaptation; attitudes toward immigration; community; immigrants' reception; integration; migrants' perspective; perceived health; well-being

\section{Issue}

This editorial is part of the issue "Immigration from the Migrants' Perspective" edited by Alice Ramos (Institute of Social Sciences, Portugal), Eldad Davidov (University of Cologne, Germany/University of Zurich, Switzerland), Peter Schmidt (University of Giessen, Germany), Marta Vilar Rosales (Institute of Social Sciences, Portugal) and Dina Maskileyson (University of Cologne, Germany).

(C) 2019 by the authors; licensee Cogitatio (Lisbon, Portugal). This article is licensed under a Creative Commons Attribution 4.0 International License (CC BY).

Immigration has been one of the most crucial global phenomena changing the fabric of many societies, and a topic of substantial research. Much of this research has focused on how the host society views immigrants and immigration or on the societal factors influencing immigration. The goal of this thematic issue is to present different studies focusing on various aspects of immigration from a perspective that has not been often viewed under the magnifying glass so far, but which is of major importance: looking at immigration from the immigrants' point of view.

Natives' attitudes toward immigration have been thoroughly analyzed in the literature using survey data.
A multitude of articles contributing to the study of citizens' attitudes and opinions about immigrants and immigration policies, including their determinants and consequents, have been published based on survey data, for example, from the European Social Survey (Heath et al., 2019) or other international large-scale surveys. Indeed, opposition of members of the host society to immigration, their perceptions of threat due to immigrants and immigration, or preferences regarding immigration and integration policies, are just some of the topics that have been addressed from the perspective of the host society members (Ceobanu \& Escandell, 2010; Hainmueller \& Hopkins, 2014). However, and in spite of the consider- 
able number of qualitative, ethnography-based research projects focusing on the point of view of immigrants, we lack extensive survey-based work on immigrants' experience of immigration and their opinions or attitudes about immigration. Indeed, little is known about immigrants' own experience of immigration, about how immigrant populations and communities evaluate the arrival of other immigrants into the country, their political interests, their health or well-being, or their contact with natives. In reality, immigrants may possess multiple identities: On the one hand, they are conceived of as immigrants from the point of view of natives; on the other hand, they are in the process of integrating into the host society themselves, they may experience difficulties associated with immigration, and may in turn be threatened by new immigrants. This thematic issue includes studies that analyze, in a theory-driven way and using survey data, such various aspects of immigrants' experience in the host society, like political interest and participation (Hochman \& García-Albacete, 2019), attitudes toward other immigrants (Becker, 2019), wellbeing (Sarrasin, Green, Potarca, Bolzman, \& Kuhn, 2019), perceived health (Maskileyson, Semyonov, \& Davidov, 2019), contact with natives (Bohrer, Friehs, Schmidt, \& Weick, 2019), or adaptation and integration into the host society (Rodríguez-Puertas \& Ainz, 2019). These questions are focused on in these studies from a comparative or longitudinal perspective.

The first article, by Hochman and García-Albacete (2019), studies whether-and to what extent-youth with and without an immigration background engage with politics by looking at differences in political interest among immigrants, their offspring, and natives. Indeed, political interest is considered an important aspect of immigrants' integration into the host society. The authors focus on four European countries, England, Germany, the Netherlands, and Sweden, using data from the CILS4EU project ( $N=11,747$ respondents). Relying on social identity theory, they expect a link with national identification and political interest. Their findings show that respondents with an immigration background who also have a strong national identification with their host country are more likely to report political interest than natives. By way of contrast, respondents with an immigration background, who have a low national identification, are less likely to report political interest than natives. While national identification was of little importance for political interest of young people in Sweden, it was significant in Germany.

Becker (2019) investigates whether there are any differences in attitudes toward immigration between immigrants and natives. The author used pooled data from the 2008-2016 rounds of the American General Social Survey. The subsample included 7,362 respondents, 2,811 of whom had a migration background of the first, second, or third generation. Relying on social distance and contact theory, the study demonstrated that first-generation immigrants had, as expected, more fa- vorable attitudes toward immigration compared to those without a migration background. However, the attitudes of second- and third-generation immigrants did not differ significantly from those of natives.

Sarrasin et al. (2019) combine two explanations for the native-immigrant gap in well-being. The first suggests that low parental well-being is transmitted to their offspring, thus deteriorating offspring's well-being. The second suggests that immigrants suffer from a higher economic pressure which is in turn transmitted to their offspring and lowers offspring's well-being. The study employs data from the Swiss Household Panel $(N=1,354)$ to examine the extent to which immigrant background and economic pressures relate to well-being of adolescents and young adults through the negative affect experienced by their mothers and fathers. The findings demonstrated that young people with foreign roots were more likely to live in a household that experienced economic pressures, which, in turn, was related to impaired parental well-being which was then in turn related to an impaired own well-being. An immigration background, economic pressures, and parental wellbeing were all related to young people's negative affect.

Maskileyson et al. (2019) examine whether the "healthy immigrant effect" thesis observed in the American context prevails also in the West European context. According to the healthy immigrant effect, immigrants are expected to be healthier than the native population. This effect has been observed repeatedly in immigration countries like the USA, Canada, or Australia. Four countries were analyzed-Austria, France, Germany, and the Netherlands-using the Gender and Generations Survey (Austria $N=3,892$, France $N=8,731$, Germany $N=8,052$, and the Netherlands $N=7,219)$. Unlike previous findings, in these European countries, immigrants reported worse health than natives, thus, not lending support to the effect. The study tries to suggest several explanations for the findings in the specific West European context.

Bohrer et al. (2019) explore whether, and to what extent, contact between native East and West Germans and foreigners has changed in the last four decades, employing ALLBUS data collected between 1980 and 2016. The authors evidence a large increase in contact over these 36 years. Furthermore, the study also employs four waves of the GESIS access panel data collected between 2015 and 2016 in Germany to test the contact theory and examine whether and to what extent positive contact with immigrants is linked with more positive attitudes toward immigrants (or vice versa) among German respondents. Although there was some evidence for such a link in the data, the effects were much smaller than in other previous cross-sectional studies, and they were also mixed, depending on the method of analysis used.

Finally, Rodríguez-Puertas and Ainz (2019) conduct indepth interviews with young Spanish migrants and analyze data obtained from these interviews and from discussion groups to understand the migration process and 
sociocultural integration of those migrants in their host countries. They describe and explain changes in their perceptions of both their home and host societies. We hope that the thematic issue and the studies included in it further contribute to a better understanding of immigrants' experience in contemporary societies.

\section{Acknowledgments}

All academic editors would like to thank the editorial team of Social Inclusion for their support during work on this thematic issue. The academic editors would also like to thank Lisa Trierweiler for the English proof of this editorial. The work of Eldad Davidov was supported by the University of Zurich Research Priority Program "Social Networks."

\section{Conflict of Interests}

The authors declare no conflict of interests.

\section{References}

Becker, C. C. (2019). The influence of a migration background on attitudes towards immigration. Social Inclusion, 7(4), 279-292.

Bohrer, B., Friehs, M.-T., Schmidt, P., \& Weick, S. (2019). Contacts between natives and migrants in Germany: Perceptions of the native population since 1980 and an examination of the contact hypotheses. Social Inclusion, 7(4), 320-331.
Ceobanu, A. M., \& Escandell, X. (2010). Comparative analyses of public attitudes toward immigrants and immigration using multinational survey data: A review of theories and research. Annual Review of Sociology, 36, 309-328. https://doi.org/10.1146/ annurev.soc.012809.102651

Hainmueller, J., \& Hopkins, D. J. (2014). Public attitudes toward immigration. Annual Review of Political Science, 17, 225-249. https://doi.org/10.1146/ annurev-polisci-102512-194818

Heath, A., Davidov, E., Ford, R., Green, E. G. T., Ramos, A., \& Schmidt, P. (2019). Contested terrain: Explaining divergent patterns of public opinion towards immigration within Europe. Journal of Ethnic and Migration Studies. Advanced online publication. https:// doi.org/10.1080/1369183X.2019.1550145

Hochman, O., \& García-Albacete, G. (2019). Political interest among European youth with and without an immigrant background. Social Inclusion, 7(4), 257-278.

Maskileyson, D., Semyonov, M., \& Davidov, E. (2019). In search of the healthy immigrant effect in four west European countries. Social Inclusion, 7(4), 304-319.

Rodríguez-Puertas, R., \& Ainz, A. (2019). Nostalgic, converted, or cosmopolitan: Typology of young Spanish migrants. Social Inclusion, 7(4), 332-342.

Sarrasin, O., Green, E. G. T., Potarca, G., Bolzman, C., \& Kuhn, U. (2019). Feeling blue by extension: Intrafamily transmission and economic pressures explain the native-immigrant gap in well-being among youth in Switzerland. Social Inclusion, 7(4), 293-303.

\section{About the Authors}
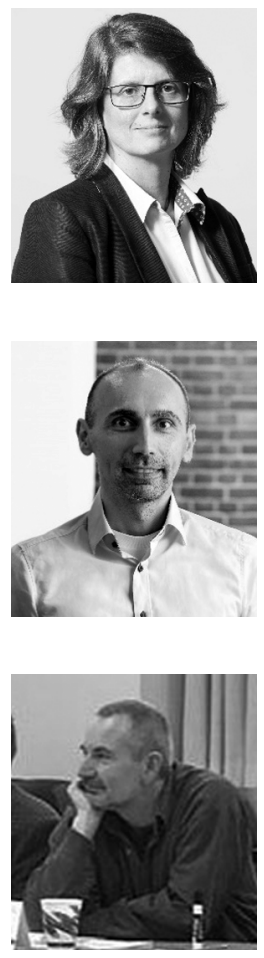

Alice Ramos, PhD in Sociology by the University of Lisbon, is a Researcher at the Institute of Social Sciences (ICS), University of Lisbon. Her academic core interests follow two main lines of research: one aiming to analyze the impact of the articulation between individual factors (values and attitudes) and social contexts in the development of discriminatory attitudes; another, focused on the methodology of comparative and longitudinal studies and on advanced methods of data analysis. She is currently the Portuguese national coordinator of the European Social Survey and the European Values Study.

Eldad Davidov is Professor at the Institute for Sociology and Social Psychology at the University of Cologne, Germany, and the Department of Sociology at the University of Zurich, Switzerland, and codirector of the University of Zurich Research Priority Program "Social Networks." He was president of the European Survey Research Association (ESRA) between 2015 and 2017. His research interests are applications of structural equation modeling to survey data, especially in cross-cultural and longitudinal research. Applications include human values, national identity, and attitudes toward immigrants and other minorities.

Peter Schmidt is Professor Emeritus of Social Research Methods and Political Science at the University of Giessen, at the department of political science, Germany. His research interests are the foundations and applications of structural equation models, analysis of panel data, and empirical testing of rational choice theory. Applications include national identity, immigration, and environmental behavior. 

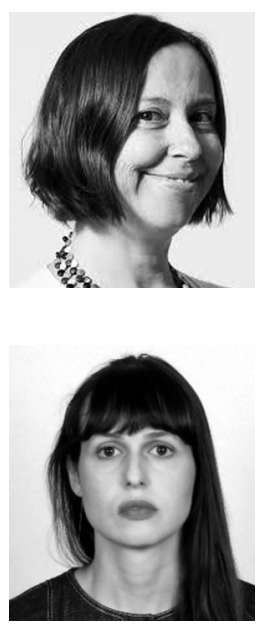

Marta Vilar Rosales, PhD in Anthropology, is a Researcher at Institute of Social Sciences, University of Lisbon. Her main field of research is contemporary migration movements in and out of Portugal and their intersections with the movements of things. She has done ethnographic research in Mozambique, Brazil, Canada and the USA, and is currently engaged in a large research project which involves the transits of people and stuff between four major cities: Lisboa, Sidney, Berlin and Luanda. She is a member of IMISCOE-A European Network of Excellence on Migration Studies.

Dina Maskileyson is Postdoctoral Researcher at the Institute of Sociology and Social Psychology at the University of Cologne. Her research interests lie in the areas of immigration, health, and labor market and wealth inequality. Her recent publications focus on immigrants' labor market integration as well as health trajectories of immigrants after the arrival to the host country. 